\title{
Differential vulnerability of white matter structures to experimental infantile hydrocephalus detected by diffusion tensor imaging
}

\author{
Ramin Eskandari • Osama Abdullah • Cameron Mason • \\ Kelley E. Lloyd • Amanda N. Oeschle • \\ James P. McAllister II
}

Received: 23 April 2014 / Accepted: 14 July 2014 / Published online: 29 July 2014

(C) Springer-Verlag Berlin Heidelberg 2014

\begin{abstract}
Purpose The differential vulnerability of white matter (WM) to acute and chronic infantile hydrocephalus and the related effects of early and late reservoir treatment are unknown, but diffusion tensor imaging (DTI) could provide this information. Thus, we characterized WM integrity using DTI in a clinically relevant model.

Methods Obstructive hydrocephalus was induced in 2-weekold felines by intracisternal kaolin injection. Ventricular reservoirs were placed 1 (early) or 2 (late) weeks post-kaolin and tapped frequently based solely on neurological deficit. Hydrocephalic and age-matched control animals were sacrificed 12 weeks postreservoir. WM integrity was evaluated in the optic system, corpus callosum, and internal capsule prereservoir and every 3 weeks using DTI. Analyses were grouped as acute ( $<6$ weeks) or chronic $(\geq 6$ weeks).

Results In the corpus callosum during acute stages, fractional anisotropy (FA) decreased significantly with early and late reservoir placement ( $p=0.0008$ and 0.0008 , respectively), and diffusivity increased significantly in early (axial, radial, and
\end{abstract}

R. Eskandari

Stanford Children's Health, Lucile Packard Children's Hospital, 725

Welch Road, Palo Alto, CA, USA

O. Abdullah · J. P. McAllister II

Department of Bioengineering, University of Utah, Salt Lake City, UT, USA

C. Mason · K. E. Lloyd · A. N. Oeschle • J. P. McAllister II Department of Neurosurgery, Division of Pediatric Neurosurgery, Primary Children's Medical Center, University of Utah, Salt Lake City, UT, USA

R. Eskandari $(\square)$

96 Jonathon Lucas St., Suite 301 MSC 606, Charleston,

SC 29425, USA

e-mail: eskandar@musc.edu mean diffusivity, $p=0.0026,0.0012$, and 0.0002 , respectively) and late (radial and mean diffusivity, $p=0.01$ and 0.0038 , respectively) groups. Chronically, the corpus callosum was thinned and not detectable by DTI. FA was significantly lower in the optic chiasm and tracts $(p=0.0496$ and 0.0052 , respectively) with late but not early reservoir placement. In the internal capsule, FA in both reservoir groups increased significantly with age $(p<0.05)$ but diffusivity remained unchanged.

Conclusions All hydrocephalic animals treated with intermittent ventricular reservoir tapping demonstrated progressive ventriculomegaly. Both reservoir groups demonstrated WM integrity loss, with the $\mathrm{CC}$ the most vulnerable and the optic system the most resilient.

Keywords Infantile hydrocephalus · Diffusion tensor imaging $\cdot$ White matter

\section{Introduction}

Our understanding of infantile hydrocephalus pathophysiology contains many knowledge gaps, including a lack of insight into how white matter from periventricular and deep brain regions is injured. The effects of hydrocephalus on white matter damage have been reported previously, but to our knowledge, experimentally measured effects during treatment over a long period of time have not been described. Furthermore, little is known about how damage to white matter from hydrocephalus evolves over time [1-4]. Thus, it is difficult to determine whether damage occurs prior to or during treatment of hydrocephalus. Diffusion tensor imaging (DTI), a modality of magnetic resonance (MR) imaging, has emerged as a very useful tool in assessing structural changes within the body, especially within the white matter of the brain [5-21]. In this 
experimental study, we investigated DTI changes in various white matter structures known to be damaged in hydrocephalus to determine whether this modality could identify where and when damage is occurring during infantile hydrocephalus $[2$, 3, 22-24]. We hypothesized that within the developing brain of infant hydrocephalic animal, differences in white matter damage could be detected by DTI and the periods of white matter vulnerability during treatment could be identified.

Cellular structures that are organized in directional bundles, such as the optic tract and internal capsule, restrict diffusion of water molecules more than gray matter does. By identifying the restriction of water molecule diffusion in a given direction (anisotropy) through regions of interest (ROIs) in the brain, DTI quantifies the directionality of specific cellular structures. DTI utilizes fractional anisotropy (FA) as a measure of the amount of directional restriction of various ROIs. FA is a universal scalar value between 0 and 1 , where 0 is unrestricted diffusion in all directions and 1 is complete restriction of diffusion to one-directional axis. In the brain, more tightly bundled and more myelinated white matter structures allow more restriction of water diffusion in one directional axis, and therefore have a higher FA value [9, 25-33]. When the microstructure of white matter bundles is disrupted (i.e., by trauma) or before they are organized into tight bundles (i.e., prematurity), the FA values are lower [26, 32, 34-39]. Furthermore, in such cases where water diffusion is not restricted (i.e., trauma and prematurity), the diffusivity (a second quantifiable measure used in DTI) increases. Thus, a decrease in FA as well as an increase in diffusivity values may signal damage to white matter structures.

Limitations to our investigation of how hydrocephalus damages the brain are inherent in human studies [23, 24, 40]. The definitive standard for evaluating damage continues to be histopathological analysis, which cannot be reasonably performed in infants, but this gap in our knowledge can be bridged by appropriate animal models of infantile hydrocephalus. Using our well-studied kitten model of induced infantile hydrocephalus [41-45], many pathophysiologic processes affected by hydrocephalus can be assessed, including neurologic deficits, ventricular size, cerebrospinal fluid (CSF) biomarkers, histopathology, and structural integrity of white matter tracts [46]. Our animal model of infantile hydrocephalus allows us to take advantage of advanced MR imaging and DTI to follow white matter development, maturation, and, perhaps most importantly, damage and dysfunction.

Identifying damage to the integrity of white matter structures within the developing brain, quantifying the temporal relationship between the onset of ventriculomegaly and white matter damage, and determining which white matter structures in the developing brain are more susceptible to damage and what the mechanism of that damage is (e.g., axonal damage, demyelination, and dysmyelination) are critical to understanding the pathophysiology of infantile hydrocephalus. To help answer these questions, we used DTI as a noninvasive tool that is both quantifiable and reproducible $[25,28,47]$. DTI has been used in fiber evaluation elsewhere (e.g., the ultrastructure of the heart myofibers), and its expanded use in brain imaging has made it a subject of increasing interest in the study of infantile hydrocephalus $[9,48]$. DTI studies in hydrocephalic patients have suggested certain white matter regions are vulnerable to the detrimental effects of hydrocephalus [5, 49]. Recent studies of infants with hydrocephalus also have correlated neurologic deficits with changes in brain DTI $[5,9,10,17,49-52]$.

We evaluated various white matter structures that are known to be affected by hydrocephalus through DTI to quantify their susceptibility to damage and to determine whether DTI could be used to assess the mechanism of damage. We also discuss what DTI changes may represent in each of these ROIs: axonal damage, myelin sheath alterations, or repair mechanisms within the vulnerable neonatal brain.

\section{Methods}

\section{Experimental design}

Experimental methods using neonatal feline hydrocephalus models have been well described by us and others [22, 41, 42, 53-59]. Briefly, $25 \%$ sterile kaolin was injected percutaneously into the cisterna magna of anesthetized animals. After ventriculomegaly was confirmed by MR imaging, the animals were divided into two groups; in the early and late groups, ventricular reservoirs were implanted 7 and 14 days after kaolin injection, respectively. Age-matched controls (non-kaolin-injected and kaolin-injected but nonhydrocephalic animals) were used for each group. All animals underwent surgical implantation of a preassembled ventricular catheter and subcutaneous reservoir (Integra Scientific, Plainsboro, NJ, USA and Medtronic, Inc., Minneapolis, MN, USA). Detailed surgical techniques, including perioperative monitoring of vital signs, have been previously described [42]. The ventricular catheter was inserted through a burr hole approximately $2 \mathrm{~mm}$ posterior to the coronal suture and $2 \mathrm{~mm}$ lateral to the sagittal suture. No CSF drainage occurred distal to the reservoir. Neurologic assessments were completed at least daily to assess neurologic status and to determine the need for reservoir tapping. Control animals underwent identical neurologic assessment alongside animals in the treatment groups. Subcutaneous ventricular reservoirs were tapped on an individual basis according to strict clinical criteria characterizing neurological deficit, as described previously [42].

\section{MR imaging acquisition}

All animals received anatomical T2-weighted MR imaging scans with DTI sequences before reservoir placement, postoperatively within 1 week of reservoir placement, and then at 
3, 6, 9, and 12 weeks after reservoir placement. All animal were monitored before, during, and after all sedation procedures to ensure that routine vital signs (heart rate, $\mathrm{SpO} 2$, core temperature, and respiration) remained within acceptable limits, as described previously [42]. Any animal that required more time to fully regain consciousness and reflexes after anesthetic procedures was also monitored closely so that they would not become cold or dehydrated. Data were reported as average DTI values obtained in the acute period $<6$ weeks or in the chronic period $\geq 6$ weeks after reservoir placement. The former includes all DTI data from prereservoir, immediate postoperative, and 3-week time points, whereas data from $\geq 6$ weeks includes those DTI data from 6,9 , and 12 weeks postreservoir placement.

Imaging experiments were conducted on a 7-T Bruker Biospec horizontal bore MR imaging scanner (Bruker Biospin, Billerica, MA, USA) interfaced with actively shielded gradient inserts of 120 or $200 \mathrm{~mm}$ inner diameter (ID) depending on the animal size and age. Animals were anesthetized using 1-3\% isoflurane and $2 \mathrm{~L} / \mathrm{min} \mathrm{O}_{2}$; vital signs (heart rate, oxygen saturation, respiration rate, and rectal temperature) were continuously monitored using a MRcompatible physiological monitoring system (SA Instruments, Stony Brook, NY, USA). Animals' temperatures were kept at $38{ }^{\circ} \mathrm{C}$ using a computer-controlled warm air heater system. Imaging time was limited to $<30 \mathrm{~min}$ for younger animals (postreservoir MR imaging 3 and 6 weeks) because of lower anesthesia tolerance. Depending on the head size, MR signal transmission and reception was accomplished using a volume coil with ID of either $72 \mathrm{~mm}$ (Bruker Biospin) or $90 \mathrm{~mm}$ (m2m Imaging Corp, OH, USA). The T2-weighted images were acquired using a fast spin echo sequence with $5,100 \mathrm{~ms}$ repetition time (TR), $50 \mathrm{~ms}$ echo time (TE), 8 echoes per image, 2 averages, 30 coronal slices of $1.5 \mathrm{~mm}$ slice thickness,
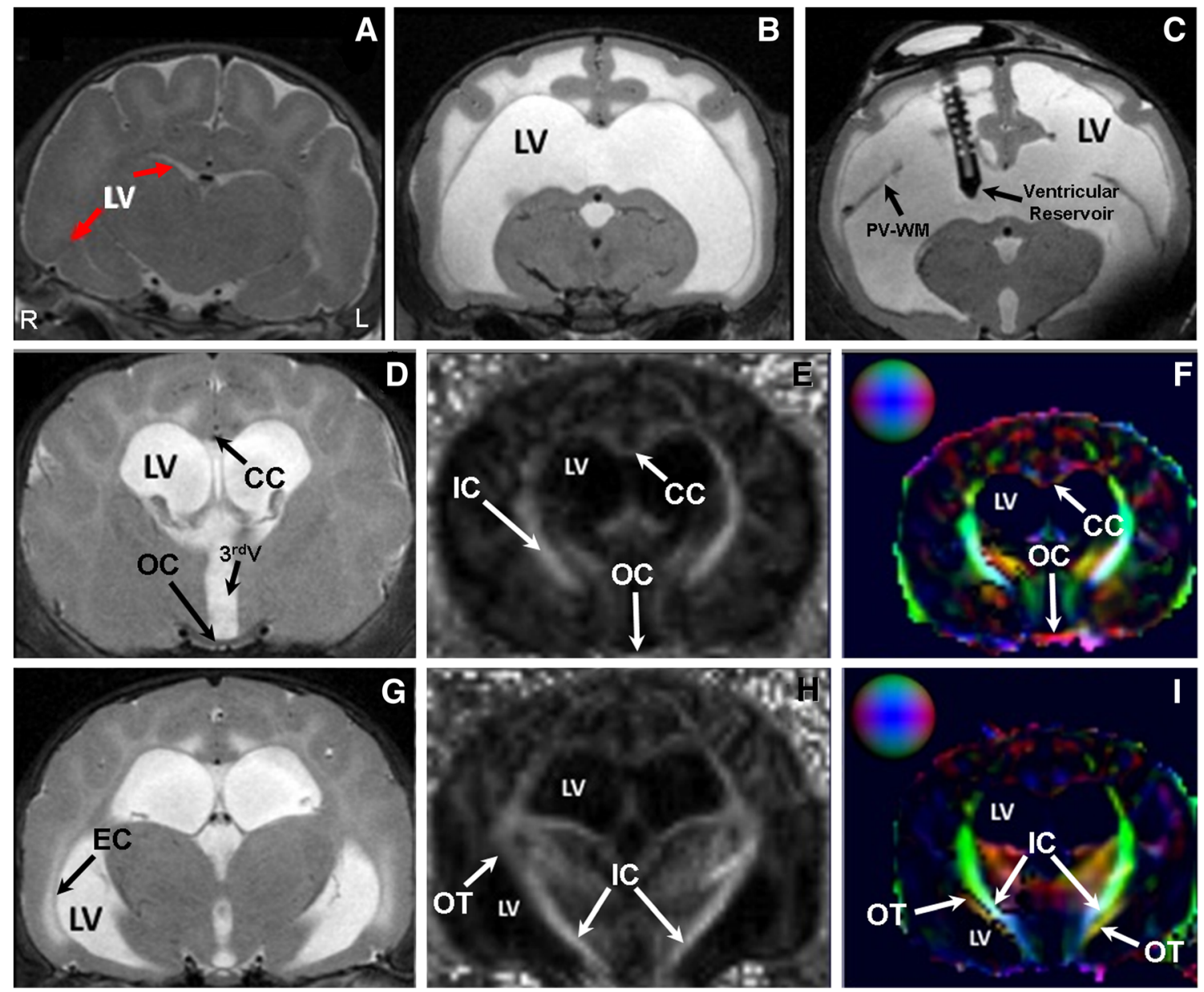

Fig. 1 Representative MRI/DTI from early group prereservoir treatment demonstrating white matter regions of interest in DTI $(\mathbf{a}, \mathbf{d}, \mathbf{g})$, tractography color maps $(\mathbf{b}, \mathbf{e}, \mathbf{h})$, and T2-weighted images $(\mathbf{c}, \mathbf{f}, \mathbf{i})$. The corpus callosum $(C C)$ is thinned when the ventricles are dilated but is detectable on DTI at this early stage: fibers from the $\mathrm{CC}$ are seen on the color map as red/purple, indicating lateral crossing fibers. These fibers are lost on MRI/DTI and color maps after 3 weeks of reservoir treatment. The fibers of the internal capsule (IC) run in the anterior-posterior direction as well as superior-inferior and are seen as green on color maps. The IC is medial (a) and posterior $(\mathbf{d}, \mathbf{g})$ to the optic tract $(O T)$, which runs anterior and lateral from the optic chiasm $(O C)$ to the lateral nucleus of the thalamus. Fibers of the $\mathrm{OC}$ are also seen as red/purple because of their lateral crossing nature. The external capsule $(E C)$ is stretched along the outer wall of the lateral ventricle (LV) and is one of the first structures lost with progressive hydrocephalus. $3 r d V$ Third ventricle 

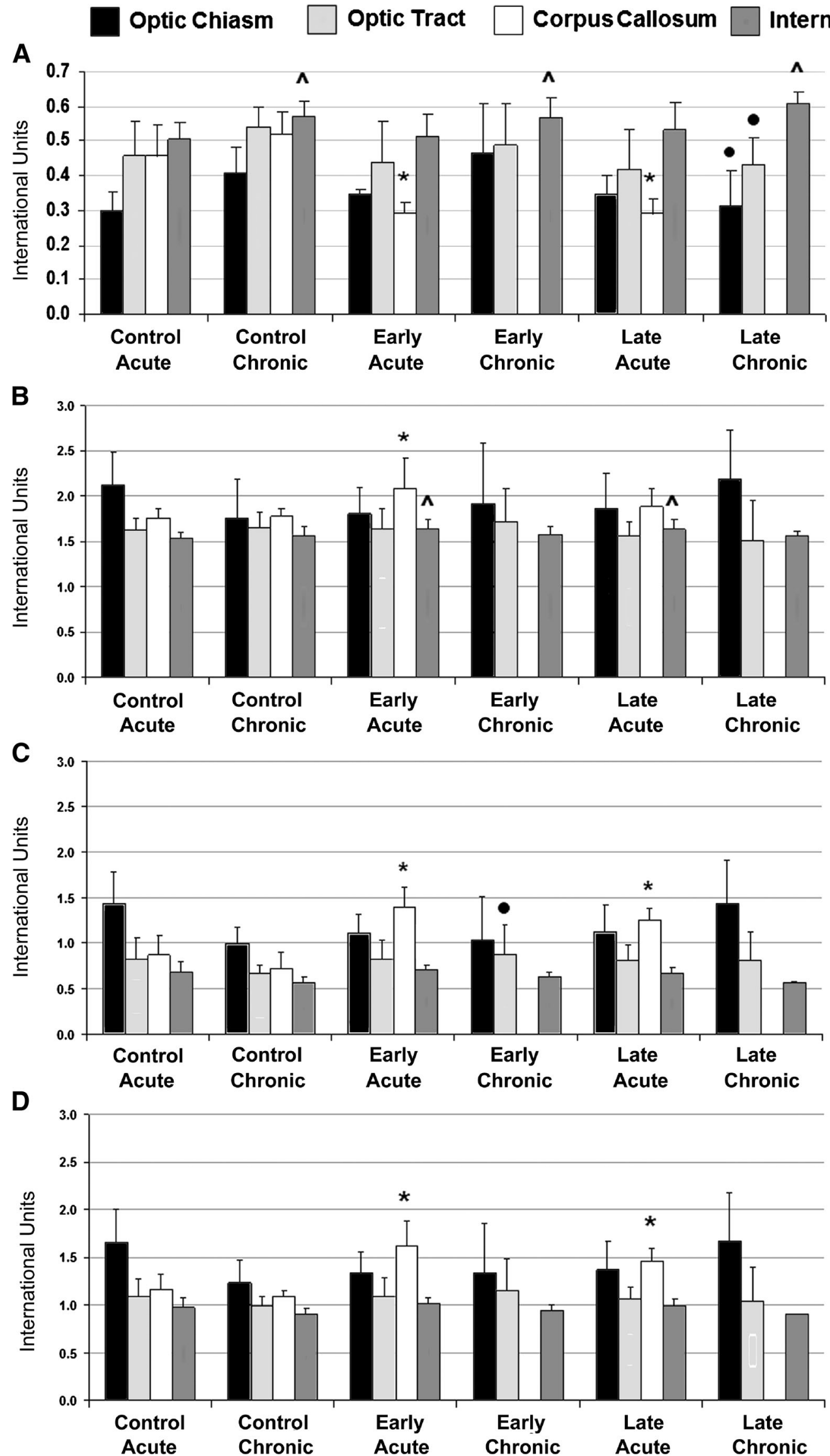
4 Fig. 2 Diffusion tensor parameters for the optic chiasm (black), optic tract (light gray), corpus callosum (white), and internal capsule (dark gray) within control, early, and late groups $<6$ (acute) and $\geq 6$ (chronic) weeks after reservoir placement. a $F A$ fractional anisotropy. FA in the corpus callosum $(C C)$ in the acute phase (CC obliterated and not available for analysis in the chronic phase) was significantly decreased in both the early and late groups compared with controls $(* p=0.0008)$. Likewise, in the optic chiasm and tract FA of the chronic phase was significantly decreased in the late group compared with controls $(p<0.05)$. In contrast, in the internal capsule FA was significantly increased in the chronic phase compared with the acute phase in all groups $\left(\wedge^{\wedge}<0.05\right)$. b Axial diffusivity (AD) in the corpus callosum was significantly increased compared with controls $\left({ }^{*} p<0.05\right)$ in the acute phase; this pattern of an $\mathrm{AD}$ increase in the acute phase compared with controls was repeated in the internal capsule $\left({ }^{\wedge} p<0.05\right)$. c Radial diffusivity (RD) was significantly increased compared with controls in the corpus callosum $\left({ }^{*} p<0.01\right)$ and significantly decreased in the optic tract in the early group $(p<0.05)$. d Mean diffusivity $(M D)$ in the corpus callosum was significantly increased in the early and late groups in the acute phase compared with controls $\left({ }^{*} p<0.01\right)$. Overall, these results indicate that white matter integrity in both reservoir groups was compromised during the progression of ventriculomegaly, with the corpus callosum appearing most vulnerable and the optic system the most resilient

$50 \times 50 \mathrm{~mm}$ field of view, $256 \times 256$ acquisition matrix, yielding a $0.195 \times 0.195 \mathrm{~mm}$ in-plane resolution, and $5.5 \mathrm{~min}$ of scan time. DTI scans were acquired using a spin echo sequence with single short echo planar imaging readout and Stejskal Tanner diffusion-weighted gradients placed around the refocusing radiofrequency pulse [28, 30, 60]. Imaging parameters of the DTI scans were 3,760 ms TR, $52 \mathrm{~ms} \mathrm{TE}$, 15 coronal slices with $2 \mathrm{~mm}$ slice thickness, $50 \times 50 \mathrm{~mm}$ field of view, $96 \times 6$ acquisition matrix, yielding a $0.512 \times 0.512 \mathrm{~mm}$ in-plane resolution. Diffusion-encoding gradients were $7 \mathrm{~ms}$ long $(\delta)$ and 20-ms diffusion time $(\Delta)$, the gradient strength was $18 \%$ of the maximum available gradient yielding a nominal $b$ value of $700 \mathrm{~s} / \mathrm{mm}^{2}$. Five nondiffusion-weighted images and 30 diffusion-encoded images with gradient directions optimized over a unit sphere were used. To improve signal-to-noise ratio (SNR), the 30 diffusion directions were repeated twice. SNR for a single nondiffusion-weighted image was 30:1 (before averaging) for an ROI taken in the internal capsule region. Total time for the DTI scan was approximately $4 \mathrm{~min}$.

For older animals (postreservoir MR imaging 9 and 12 weeks), the larger gradient set (200 mm ID) and a larger radiofrequency coil (150 $\mathrm{mm}$ ID) (Bruker Biospin) were used. Similar T2 and DTI imaging protocols were employed as the smaller gradient set, with exception of the following parameters. For T2 scans, the field of view was $70 \times 70 \mathrm{~mm}$, in-plane resolution was $0.273 \times 0.273 \mathrm{~mm}$, and $2 \mathrm{~mm}$ slice thickness was used. For the DTI scan, TE was $70 \mathrm{~ms}$, diffusion encoding gradients had a $\delta$ of $15 \mathrm{~ms}, \Delta$ of $20 \mathrm{~ms}$, and diffusion gradient strength was $18 \%$ of maximum available gradient yielding a nominal $b$ value of $700 \mathrm{~s} / \mathrm{mm}^{2}$. Eight repeats of the 30 diffusion directions scheme was used to improve the tensor fitting accuracy. The SNR of the nondiffusion-weighted image (before averaging) was approximately 30:1 in a ROI taken in the internal capsule region. Total time for the DTI scan was $15 \mathrm{~min}$.

DTI image analysis was conducted using the manufacturer's DTI processing software Paravision 5.0. ROIs were manually selected including midline corpus callosum, internal capsule (left and right), external capsule (left and right), optic tract (left and right), and the midline optic chiasm. Mean DTI eigenvalues for each of these ROIs were used to perform statistical analyses for FA, mean diffusivity (MD), axial diffusivity (AD), and radial diffusivity (RD).

\section{Statistical analysis}

Analysis of variance was used to compare the experimental groups in both acute ( $<6$ weeks after reservoir placement) and chronic ( $\geq 6$ weeks after reservoir placement) periods. Control animals were compared by using age-matched assessment of acute and chronic phases. A Shapiro-Wilk test showed that diffusion tensor parameters were normally distributed; therefore, mean FA, MD, AD, and RD were compared by twosided $t$ tests. A $p$ value of $<0.05$ was considered to be statistically significant.

\section{Results}

Thirty-seven animals were used for this study. Twelve animals in the experimental group were not included in the final data analysis because of failure to thrive, infection, or inability to tolerate anesthesia. Twenty-five animals were therefore used for the final analysis - nine were included in the early reservoir group, nine in the late reservoir group, and seven in the nonhydrocephalic animals were used as control animals. For comparisons to each of the reservoir-treated experimental groups (early and late), age-matched control DTI scans were obtained using nonhydrocephalic animals.

Each group of animals exhibited considerable ventriculomegaly throughout the study period (Fig. 1; see also [42]) that was accompanied by significant changes in various white matter regions (Fig. 2; Table 1). No significant differences were noted between the right and left sides of the optic chiasm, optic tract, or internal capsule, and therefore left and right data points for each of these regions were pooled.

Optic chiasm and optic tracts

Within the optic chiasm, significant differences were noted between the chronic late and control groups. Mean FA decreased from $0.408 \pm 0.074$ to $0.313 \pm 0.100(p=0.0496)$. Mean MD differences between these groups were nearly significant $(1.233 \pm 0.241$ vs. $1.679 \pm 0.499, p=0.061)$. No significant changes were seen among any of the optic chiasm measurements in other groups. 
Table 1 Changes in white matter regions as measured on DTI

\begin{tabular}{|c|c|c|c|c|c|c|c|c|c|c|c|c|}
\hline \multirow[b]{2}{*}{ Group } & \multicolumn{3}{|c|}{ Optic chiasm } & \multicolumn{3}{|c|}{ Optic tract } & \multicolumn{3}{|c|}{ Corpus callosum } & \multicolumn{3}{|c|}{ Internal capsule } \\
\hline & Mean & SD & $n$ & Mean & SD & $n$ & Mean & SD & $n$ & Mean & SD & $n$ \\
\hline \multicolumn{13}{|c|}{ Fractional anisotropy } \\
\hline Control acute & 0.299 & 0.053 & 6 & 0.458 & 0.100 & 8 & 0.457 & 0.089 & 8 & 0.506 & 0.048 & 9 \\
\hline Control chronic & 0.408 & 0.074 & 23 & 0.540 & 0.058 & 24 & 0.521 & 0.066 & 24 & $0.570^{\dagger \dagger}$ & 0.046 & 24 \\
\hline Early acute & 0.346 & 0.015 & 18 & 0.441 & 0.120 & 18 & $0.290^{\S \S \S}$ & 0.031 & 20 & 0.517 & 0.061 & 20 \\
\hline Early chronic & 0.468 & 0.139 & 14 & 0.488 & 0.119 & 14 & $\mathrm{n} / \mathrm{a}$ & $\mathrm{n} / \mathrm{a}$ & 0 & $0.567^{\dagger}$ & 0.056 & 11 \\
\hline Late acute & 0.348 & 0.052 & 14 & 0.418 & 0.115 & 14 & $0.291^{* * *}$ & 0.045 & 15 & 0.531 & 0.081 & 15 \\
\hline Late chronic & $0.313^{*}$ & 0.100 & 7 & $0.434^{* *}$ & 0.079 & 8 & $\mathrm{n} / \mathrm{a}$ & $\mathrm{n} / \mathrm{a}$ & 0 & $0.607^{*}, \dagger$ & 0.037 & 8 \\
\hline \multicolumn{13}{|l|}{ Axial diffusivity } \\
\hline Control acute & 2.117 & 0.377 & 5 & 1.626 & 0.134 & 8 & 1.758 & 0.109 & 6 & 1.534 & 0.073 & 6 \\
\hline Control chronic & 1.764 & 0.417 & 18 & 1.655 & 0.172 & 24 & 1.774 & 0.094 & 23 & 1.567 & 0.097 & 23 \\
\hline Early acute & 1.803 & 0.291 & 18 & 1.640 & 0.230 & 18 & $2.076^{\S \S}$ & 0.349 & 18 & $1.648^{\S}$ & 0.095 & 18 \\
\hline Early chronic & 1.916 & 0.667 & 14 & 1.724 & 0.360 & 14 & $\mathrm{n} / \mathrm{a}$ & $\mathrm{n} / \mathrm{a}$ & 0 & 1.582 & 0.085 & 11 \\
\hline Late acute & 1.858 & 0.396 & 14 & 1.556 & 0.164 & 14 & 1.882 & 0.204 & 13 & $1.634^{*}$ & 0.112 & 13 \\
\hline Late chronic & 2.184 & 0.544 & 7 & 1.511 & 0.438 & 8 & $\mathrm{n} / \mathrm{a}$ & $\mathrm{n} / \mathrm{a}$ & 0 & 1.558 & 0.055 & 2 \\
\hline \multicolumn{13}{|l|}{ Radial diffusivity } \\
\hline Control acute & 1.427 & 0.351 & 5 & 0.824 & 0.236 & 8 & 0.867 & 0.217 & 6 & 0.687 & 0.162 & 6 \\
\hline Control chronic & 0.987 & 0.181 & 18 & 0.665 & 0.090 & 24 & 0.715 & 0.185 & 24 & 0.574 & 0.068 & 23 \\
\hline Early acute & 1.118 & 0.201 & 18 & 0.825 & 0.212 & 18 & $1.392^{\S \S}$ & 0.220 & 18 & 0.699 & 0.071 & 18 \\
\hline Early chronic & 1.037 & 0.473 & 14 & $0.880^{\S}$ & 0.312 & 14 & $\mathrm{n} / \mathrm{a}$ & $\mathrm{n} / \mathrm{a}$ & 0 & $0.627^{\S}$ & 0.066 & 11 \\
\hline Late acute & 1.121 & 0.288 & 14 & 0.811 & 0.164 & 14 & $1.244^{*}$ & 0.132 & 13 & 0.670 & 0.109 & 13 \\
\hline Late chronic & 1.427 & 0.483 & 7 & 0.812 & 0.311 & 8 & $\mathrm{n} / \mathrm{a}$ & $\mathrm{n} / \mathrm{a}$ & 0 & 0.574 & 0.025 & 2 \\
\hline \multicolumn{13}{|l|}{ Mean diffusivity } \\
\hline Control acute & 1.657 & 0.355 & 5 & 1.091 & 0.183 & 8 & 1.164 & 0.157 & 6 & 0.970 & 0.114 & 6 \\
\hline Control chronic & 1.233 & 0.241 & 17 & 0.995 & 0.090 & 24 & 1.089 & 0.071 & 23 & 0.905 & 0.059 & 23 \\
\hline Early acute & 1.346 & 0.219 & 18 & 1.097 & 0.196 & 18 & $1.620^{\S \S \S}$ & 0.260 & 18 & 1.015 & 0.067 & 18 \\
\hline Early chronic & 1.330 & 0.519 & 14 & 1.162 & 0.318 & 14 & $\mathrm{n} / \mathrm{a}$ & $\mathrm{n} / \mathrm{a}$ & 0 & 0.945 & 0.060 & 11 \\
\hline Late acute & 1.366 & 0.299 & 14 & 1.059 & 0.126 & 14 & $1.456^{* *}$ & 0.144 & 13 & 0.991 & 0.070 & 13 \\
\hline Late chronic & 1.679 & 0.499 & 7 & 1.045 & 0.351 & 8 & $\mathrm{n} / \mathrm{a}$ & $\mathrm{n} / \mathrm{a}$ & 0 & 0.902 & 0.002 & 2 \\
\hline
\end{tabular}

$\S_{p}<0.05$ control versus early group; ${ }^{\S} p<0.01$ control versus early group; ${ }^{\S \S} p<0.001$ control versus early group; ${ }^{*} p<0.05$ control versus late group; ${ }^{* *} p<0.01$ control versus late group; ${ }^{* * *} p<0.001$ control versus late group; ${ }^{\dagger} p<0.05$ acute versus chronic within same experimental group; ${ }^{\dagger \dagger} p<0.01$ acute versus chronic within same experimental group

Within the optic tract, mean FA in the chronic late group was significantly lower than in the control group $(0.540 \pm 0.058$ vs. $0.434 \pm 0.079, p=0.0052$ ). Mean $\mathrm{RD}$ in the chronic early group was higher than in the age-matched controls $(0.665 \pm 0.090 \mathrm{vs}$. $0.880 \pm 0.312, p=0.0258$ ). There were no significant differences in mean $\mathrm{AD}$ and $\mathrm{MD}$ within the optic tract.

\section{Corpus callosum}

Once hydrocephalic animals reached 6 weeks after reservoir placement, the corpus callosum was no longer recognizable on DTI; therefore, FA, AD, RD, and MD were unobtainable for these animals at more chronic stages. In hydrocephalic animals $<6$ weeks after reservoir placement, there was a statistically significant difference in the mean $F A, A D, R D$, and $\mathrm{MD}$ within the corpus callosum between the control and early as well as between control and late reservoir groups. Mean FA was $0.457 \pm 0.089$ in the control group and $0.290 \pm 0.031$ in the early group ( $p=0.0008)$ and $0.291 \pm 0.045$ in the late group $(p=0.0008)$. Mean $\mathrm{AD}$ was higher in the early group $(1.758 \pm$ $0.109)$ than in the control group $(2.076 \pm 0.349)(p=0.0026)$. Mean RD measurements increased from $0.867 \pm 0.217$ in control animals to $1.392 \pm 0.220$ and $1.244 \pm 0.132$ in the early ( $p=$ $0.0012)$ and the late $(p=0.01)$ groups, respectively. Mean MD also increased significantly between the control group $(1.164 \pm$ $0.157)$ and both the early $(1.620 \pm 0.260 ; p=0.0002)$ and the late $(1.456 \pm 0.144 ; p=0.0038)$ groups.

Internal capsule

Within each group (control, early, and late), the internal capsule demonstrated statistically significant age-related 
increases in mean FA in animals more than 6 weeks postreservoir compared with younger animals. In the control group, normal development was reflected by a mean FA increase from $0.506 \pm 0.048$ to $0.570 \pm 0.046 \quad(p=0.0038)$ after 6 weeks. Within the internal capsule of the early group, mean FA increased in the older animals by 0.05 compared to the younger animals $(p=0.0322)$; likewise, the age-related mean $\mathrm{FA}$ in the late group increased by 0.076 ( $p=0.0066)$.

Among the animals at the chronic stage, the mean FA of the internal capsule increased significantly from $0.570 \pm 0.046$ in the control group to $0.607 \pm 0.037$ in the late group ( $p=$ 0.0356). During the acute stage, mean AD increased from $1.534 \pm 0.073$ in the control group to $1.648 \pm 0.095$ in the early and $1.634 \pm 0.112$ in the late treatment groups $(p=0.0114$ and 0.0392 , respectively). Significant increases were also seen in RD compared with controls, but only in the early group animals $<6$ weeks $(p=0.044)$. No significant changes in mean MD were seen within the internal capsule of animals in any group or age category.

\section{Discussion}

By identifying the restriction of water molecule diffusion in a given direction (anisotropy) through different ROIs, the integrity of white matter structures is assessed. Thus, calculating the anisotropy and diffusivity in structures affected by hydrocephalus at various time points provides a better understanding of the course of hydrocephalus and how damage to white matter evolves.

Changes in water directionality during normal maturation and aging, specifically an increase in FA and a decrease in diffusivity parameters (i.e., $\mathrm{MD}, \mathrm{AD}$, and $\mathrm{RD}$ ) during brain maturation, have been well documented [5, 10, 25, 48, 61-73]. In the current study, we define such changes as advancing age-related (AAR) alterations, and the effect of these developmental changes must be considered when evaluating the potential effects of hydrocephalus in the maturing brain. Over time, the internal capsule displayed AAR increases in FA without significant changes to diffusivity parameters within all groups (control, early, and late). An increase in FA in this setting is assumed to be related to increased myelination within the internal capsule. In contrast, AAR increases in FA were not observed in the optic chiasm, optic tract, or corpus callosum; we interpret this lack of change to mean that these white matter regions were relatively mature and well-myelinated prior to the onset of hydrocephalus. Hydrocephalus-related FA or diffusivity changes in wellmyelinated regions have been reported in a limited number of clinical [6, 7, 10, 12, 16, 18, 19, 74-85] and experimental papers $[21,86,87]$. Decreased FA or increased diffusivity parameters in mature myelinated white matter regions can therefore be considered a reflection of damage to axons or loss of myelin (demyelination). The same FA/diffusivity alterations seen within areas of ongoing active myelination may signify axonal damage or improper myelination (dysmyelination) [88-90].

To our knowledge, this is the first experimental study to evaluate specific white matter tracts in the infantile hydrocephalic brain model by DTI measurements over such a long developmental period. We therefore have the unique ability to assess each ROI utilizing all the diffusion tensor parameters and to begin to make predictions on the meaning of these changes. We surmise that the following white matter structures are differentially vulnerable to the damaging effects of hydrocephalus.

\section{Optic system}

Of the ROIs evaluated in this study, the optic system may represent the most resilient of white matter structures to the effects of hydrocephalus. Within the optic system, all DTI changes, including FA decrease and diffusivity increase, occurred only $\geq 6$ weeks after reservoir placement. Although the FA values decreased in both the optic chiasm and optic tract within the late reservoir group, no changes were noted in the early animals. The RD increased in the early group, AD remained stable, and the MD increase was not significant. No diffusivity changes were noted in the late group. The constellation of changes seen in the optic system suggest overall injury to the white matter tracts of the optic tract and optic chiasm with decreasing FA values, whereas increasing $\mathrm{RD}$ in the optic tract (and a trend toward significance in MD) suggests the mechanism is alterations in the myelin sheath. Because we presume that the optic system was maturely myelinated in these animals, demyelination may be the major mechanism for white matter damage in the optic system; however, researchers such as Budde et al. [88, 91] have shown that anisotropy in the white matter areas surrounding cortical damage in an animal model can be affected by multiple aspects of white matter microstructure-namely astrocytic responses and gliosis. In their 2011 paper, Budde and colleagues demonstrated the role of organized astrocyte gliosis in the measured DTI values of FA and diffusivity parameters. Through a direct comparison of DTI and histologic sections, they provided evidence that previously presumed axonal damage/regeneration or re/demyelination may not be the only mechanisms by which DTI measurements alter after injury. We plan to histologically evaluate brains at each of the MR imaging time points to verify our hypothesis and determine the exact amount and extent to which demyelination or other mechanisms are responsible for the DTI changes seen during hydrocephalus. 


\section{Corpus callosum}

Conversely, among the structures we evaluated, the corpus callosum may represent the white matter structure most susceptible to damage from hydrocephalus. Physical stretch and compression of the callosal fibers was obvious with progressive ventriculomegaly, and 6 weeks after reservoir placement, DTI values were unobtainable within the corpus callosum. Other periventricular white matter tracts, such as the external capsule, demonstrated similar phenomena and became indistinguishable (data not shown). Unlike the optic system, where all changes in DTI values were observed after 6 weeks of reservoir placement, both decrease in FA and increase in diffusivity within the corpus callosum were observed less than 6 weeks after reservoir placement, making the effects of hydrocephalus on the corpus callosum much more immediate. A significant decrease in FA was noted in both early and late groups, and with the exception of the $\mathrm{AD}$ in the late group, significant increases in the diffusivity parameters $(\mathrm{RD}, \mathrm{AD}$, and MD) were observed in both early and late group animals. As in the optic system, white matter injury is noted from decreased FA; however, in the corpus callosum, damage was witnessed in both early and late treatment groups. Significantly increased $\mathrm{AD}$ and $\mathrm{RD}$ (also reflected as increased MD) may signify multiple mechanisms responsible for injury, including both demyelination of matured white matter tracts and direct axonal damage. Whether astrocytic mechanisms such as gliosis can also interfere with DTI parameters and decrease FA (of increase diffusivity parameters) remains to be seen in our animal mode of hydrocephalus. Budde et al. [88] have demonstrated very clearly that astrocytes play an essential role in recovery from damage, and at 4 weeks after cortical injury, chronic changes in the cortex and underlying white matter include organized astrocyte processes.

\section{Internal capsule}

Evaluation of DTI changes within the internal capsule requires consideration of the stage of myelination at each MR imaging time point. We can assume the internal capsule region was actively undergoing myelination during the experimental period because all animals including the control group displayed AAR increase in FA consistent with physiologic myelination. No decrease in FA was noted within the internal capsule and no increase in MD, making overall white matter injury a less likely scenario; however, significant increases in RD (early group) and $\mathrm{AD}$ (early and late group) were noted less than 6 weeks after reservoir placement. Such diffusivity changes are consistent with injury to white matter tract myelin as well as some amount of axonal damage, but signs of damaging effects from hydrocephalus (such as decrease in FA) that were seen in other brain regions were not noted within the internal capsule. Instead, we demonstrated an increase in the FA within the late reservoir animals $\geq 6$ weeks after treatment compared with their age-matched controls. Increase in FA in such a delayed manner may represent the capacity for delayed remyelination and axonal repair within the internal capsule. If we assume that the internal capsule was actively undergoing physiologic myelination during the experimental period, it is reasonable to assume it has the most capacity to regenerate lost myelin and repair progressively damaged axons. We must acknowledge, however, that astrocyte organization as part of the repair mechanism could also play a role in the increase in FA during the recover period after hydrocephalus. The likelihood, however, of astrocytes being a major factor in increasing FA within the internal capsule is low because similar increases were demonstrated in control animals and early and late reservoir groups. This hypothesis will be tested through histologic evaluation of the internal capsule in animals at each MR imaging time point and quantification of myelination at $3,6,9$, and 12 weeks after reservoir placement.

\section{Conclusion}

Our results suggest that various white matter regions within the developing feline brain have different susceptibilities to the damaging effects of hydrocephalus. Regions of active myelination, such as the internal capsule, may have the ability to regenerate myelin and repair demyelinated tracts more readily, while areas of high sensitivity to damage like the corpus callosum may suffer irreparable damage from hydrocephalus within a few weeks of disease progression. The visual system seems to be the most resilient to the damage from hydrocephalus seen by DTI, and changes in FA and diffusivity there are not as prominent or global.

The main question, however, remains whether radiographic changes in hydrocephalus as demonstrated by DTI can be verified through histological evaluations of cellular damage. Nevertheless, our findings in a clinically relevant model of infantile hydrocephalus demonstrate the profound regional DTI changes in white matter tracts of hydrocephalic animals treated by routine reservoir tapping.

Acknowledgments This work was supported in part by the Mentored Young Investigator award from the Hydrocephalus Association to Ramin Eskandari, MD, and James P. McAllister, PhD, and by the Department of Neurosurgery at the University of Utah. We thank Kristin Kraus, MSc, for her superb scientific editing skills; Marion L. Walker, MD, John R.W. Kestle, MD, and Jay Riva-Cambrin, MD for their inspiration and advice; Eric Burdett, DVM, Jack Taylor, DVM, Greg Burns, DVM, Ron Nielsen, DVM, Yunuen Coria, Liana Roberson, Reesha Dennis-Bishop, Jacqueline Brown, Brittani Delaney, Annette Rowberry, Misty Seppi, Kris Carlson, and Chase Bryan for their assistance with animal care and surgery. Implanted ventricular catheters and reservoirs were provided by Integra Scientific (Plainsboro, NJ, USA) and Medtronic (Medtronic Inc USA, Minneapolis, MN, USA). 


\section{References}

1. Di Curzio DL, Buist RJ, Del Bigio MR (2013) Reduced subventricular zone proliferation and white matter damage in juvenile ferrets with kaolin-induced hydrocephalus. Exp Neurol 248C: $112-128$

2. Del Bigio MR, Khan OH, da Silva LL, Juliet PA (2012) Cerebral white matter oxidation and nitrosylation in young rodents with kaolin-induced hydrocephalus. J Neuropathol Exp Neurol 71:274288

3. Khan OH, Enno TL, Del Bigio MR (2006) Brain damage in neonatal rats following kaolin induction of hydrocephalus. Exp Neurol 200: 311-320

4. Del Bigio MR, Wilson MJ, Enno T (2003) Chronic hydrocephalus in rats and humans: white matter loss and behavior changes. Ann Neurol 53:337-346

5. Cancelliere A, Mangano FT, Air EL, Jones BV, Altaye M, Rajagopal A, Holland SK, Hertzler DA 2nd, Yuan W (2013) DTI values in key white matter tracts from infancy through adolescence. Am J Neuroradiol 34:1443-1449

6. Jang SH, Choi BY, Chang CH, Jung YJ, Byun WM, Kim SH, Yeo SS (2013) The effects of hydrocephalus on the periventricular white matter in intracerebral hemorrhage: a diffuser tensor imaging study. Int J Neurosci 123:420-424

7. Nicot B, Bouzerar R, Gondry-Jouet C, Capel C, Peltier J, Fichten A, Baledent O (2013) Effect of surgery on periventricular white matter in normal pressure hydrocephalus patients: comparison of two methods of DTI analysis. Acta Radiolog 55(5):614-621

8. Yallampalli R, Wilde EA, Bigler ED, McCauley SR, Hanten G, Troyanskaya M, Hunter JV, Chu Z, Li X, Levin HS (2013) Acute white matter differences in the fornix following mild traumatic brain injury using diffusion tensor imaging. J Neuroimaging 23:224 227

9. Yuan W, McAllister JPI, Mangano FT (2013) Neuroimaging of white matter abnormalities in pediatric hydrocephalus. J Pediatri Neuroradiol 2:1-10

10. Yuan W, McKinstry RC, Shimony JS, Altaye M, Powell SK, Phillips JM, Limbrick DD Jr, Holland SK, Jones BV, Rajagopal A, Simpson S, Mercer D, Mangano FT (2013) Diffusion tensor imaging properties and neurobehavioral outcomes in children with hydrocephalus. AJNR Am J Neuroradiol 34:439-445

11. Thompson DK, Lee KJ, Egan GF, Warfield SK, Doyle LW, Anderson PJ, Inder TE (2013) Regional white matter microstructure in very preterm infants: predictors and 7 year outcomes. Cortex 52:60-74

12. Demura K, Mase M, Miyati T, Osawa T, Hattori M, Kasai H, Hara M, Shibamoto Y, Yamada K (2012) Changes of fractional anisotropy and apparent diffusion coefficient in patients with idiopathic normal pressure hydrocephalus. Acta Neurochir Suppl 113:29-32

13. Lepomaki V, Paavilainen T, Matomaki J, Hurme S, Haataja L, Lapinleimu H, Liisa LL, Komu M, Parkkola R (2012) Effect of antenatal growth and prematurity on brain white matter: diffusion tensor study. Pediatr Radiol 42:692-698

14. Lepomaki VK, Paavilainen TP, Hurme SA, Komu ME, Parkkola RK (2012) Fractional anisotropy and mean diffusivity parameters of the brain white matter tracts in preterm infants: reproducibility of regionof-interest measurements. Pediatr Radiol 42:175-182

15. Scheel M, Diekhoff T, Sprung C, Hoffmann KT (2012) Diffusion tensor imaging in hydrocephalus - findings before and after shunt surgery. Acta Neurochir (Wien) 154:1699-1706

16. Koyama T, Marumoto K, Domen K, Ohmura T, Miyake H (2012) Diffusion tensor imaging of idiopathic normal pressure hydrocephalus: a voxel-based fractional anisotropy study. Neurol Med Chir (Tokyo) 52:68-74

17. Sun M, Yuan W, Hertzler DA, Cancelliere A, Altaye M, Mangano FT (2012) Diffusion tensor imaging findings in young children with benign external hydrocephalus differ from the normal population. Childs Nerv Syst 28:199-208

18. Hattori T, Sato R, Aoki S, Yuasa T, Mizusawa H (2012) Different patterns of fornix damage in idiopathic normal pressure hydrocephalus and Alzheimer disease. AJNR Am J Neuroradiol 33:274-279

19. Hattori T, Ito K, Aoki S, Yuasa T, Sato R, Ishikawa M, Sawaura H, Hori M, Mizusawa H (2012) White matter alteration in idiopathic normal pressure hydrocephalus: tract-based spatial statistics study. AJNR Am J Neuroradiol 33:97-103

20. Feldman HM, Lee ES, Loe IM, Yeom KW, Grill-Spector K, Luna B (2012) White matter microstructure on diffusion tensor imaging is associated with conventional magnetic resonance imaging findings and cognitive function in adolescents born preterm. Dev Med Child Neurol 54:809-814

21. Yuan W, McAllister JP 2nd, Lindquist DM, Gill N, Holland SK, Henkel D, Rajagopal A, Mangano FT (2012) Diffusion tensor imaging of white matter injury in a rat model of infantile hydrocephalus. Childs Nerv Syst 28:47-54

22. McAllister JP 2nd, Cohen MI, O'Mara KA, Johnson MH (1991) Progression of experimental infantile hydrocephalus and effects of ventriculoperitoneal shunts: an analysis correlating magnetic resonance imaging with gross morphology. Neurosurgery 29:329-340

23. Del Bigio MR (2010) Neuropathology and structural changes in hydrocephalus. Dev Disabil Res Rev 16:16-22

24. Del Bigio MR (2004) Cellular damage and prevention in childhood hydrocephalus. Brain Pathol 14:317-324

25. Le Bihan D, Johansen-Berg H (2012) Diffusion MRI at 25: exploring brain tissue structure and function. Neuroimage 61:324-341

26. Kou Z, Wu Z, Tong KA, Holshouser B, Benson RR, Hu J, Haacke EM (2010) The role of advanced MR imaging findings as biomarkers of traumatic brain injury. J Head Trauma Rehabil 25:267-282

27. Sykova E, Nicholson C (2008) Diffusion in brain extracellular space. Physiol Rev 88:1277-1340

28. Mori S, Zhang J (2006) Principles of diffusion tensor imaging and its applications to basic neuroscience research. Neuron 51:527-539

29. Wozniak JR, Lim KO (2006) Advances in white matter imaging: a review of in vivo magnetic resonance methodologies and their applicability to the study of development and aging. Neurosci BiobehavRev 30:762-774

30. Basser PJ, Jones DK (2002) Diffusion-tensor MRI: theory, experimental design and data analysis - a technical review. NMR Biomed $15: 456-467$

31. Beaulieu C (2002) The basis of anisotropic water diffusion in the nervous system - a technical review. NMR Biomed 15:435-455

32. Neil J, Miller J, Mukherjee P, Huppi PS (2002) Diffusion tensor imaging of normal and injured developing human brain - a technical review. NMR Biomed 15:543-552

33. Moseley M (2002) Diffusion tensor imaging and aging - a review. NMR Biomed 15:553-560

34. Mathur AM, Neil JJ, Inder TE (2010) Understanding brain injury and neurodevelopmental disabilities in the preterm infant: the evolving role of advanced magnetic resonance imaging. Semin Perinatol 34: $57-66$

35. Suskauer SJ, Huisman TAGM (2009) Neuroimaging in pediatric traumatic brain injury: Current and future predictors of functional outcome. Develop Disabil Res Rev 15:117-123

36. Bosnell R, Giorgio A, Johansen-Berg H (2008) Imaging white matter diffusion changes with development and recovery from brain injury. Develop Neurorehabil 11:174-186

37. Sotak CH (2002) The role of diffusion tensor imaging in the evaluation of ischemic brain injury - a review. NMR Biomed 15:561-569

38. Lim KO, Helpern JA (2002) Neuropsychiatric applications of DTIa review. NMR Biomed 15:587-593

39. Jang SH (2011) A review of diffusion tensor imaging studies on motor recovery mechanisms in stroke patients. NeuroRehabilitation $28: 345-352$ 
40. Williams MA, McAllister JP, Walker ML, Kranz DA, Bergsneider M, Del Bigio MR, Fleming L, Frim DM, Gwinn K, Kestle JR, Luciano MG, Madsen JR, Oster-Granite ML, Spinella G (2007) Priorities for hydrocephalus research: report from a National Institutes of Healthsponsored workshop. J Neurosurg 107:345-357

41. Eskandari R, Harris CA, McAllister JP 2nd (2011) Reactive astrocytosis in feline neonatal hydrocephalus: acute, chronic, and shunt-induced changes. Childs Nerv Syst 27:2067-2076

42. Eskandari R, Packer M, Burdett EC, McAllister JP 2nd (2012) Effect of delayed intermittent ventricular drainage on ventriculomegaly and neurological deficits in experimental neonatal hydrocephalus. Childs Nerv Syst 28:1849-1861

43. McAllister JP 2nd (2012) Pathophysiology of congenital and neonatal hydrocephalus. Semin Fetal Neonat Med 17:285-294

44. McAllister JP II (2011) Experimental hydrocephalus. In: Winn HR (ed) Youmans textbook of neurological surgery. Elsevier, New York, pp 2002-2008

45. McAllister JP 2nd, Chovan P (1998) Neonatal hydrocephalus. Mechanisms and consequences. Neurosurg Clin N Am 9:73-93

46. Lovely TJ, McAllister JP 2nd, Miller DW, Lamperti AA, Wolfson BJ (1989) Effects of hydrocephalus and surgical decompression on cortical norepinephrine levels in neonatal cats. Neurosurgery 24:43-52

47. Zhang X, Li C (2013) Quantitative MRI measures in SIV-infected macaque brains. J Clin Cell Immunol Suppl 7:005

48. Kwon SH, Vasung L, Ment LR, Huppi PS (2014) The role of neuroimaging in predicting neurodevelopmental outcomes of preterm neonates. Clin Perinatol 41:257-283

49. Rajagopal A, Shimony JS, McKinstry RC, Altaye M, Maloney T, Mangano FT, Limbrick DD, Holland SK, Jones BV, Simpson S, Mercer D, Yuan W (2013) White matter microstructural abnormality in children with hydrocephalus detected by probabilistic diffusion tractography. AJNR Am J Neuroradiol 34:2379-2385

50. Air EL, Yuan W, Holland SK, Jones BV, Bierbrauer K, Altaye M, Mangano FT (2010) Longitudinal comparison of pre- and postoperative diffusion tensor imaging parameters in young children with hydrocephalus. J Neurosurg Pediatr 5:385-391

51. Yuan W, Mangano FT, Air EL, Holland SK, Jones BV, Altaye M, Bierbrauer K (2009) Anisotropic diffusion properties in infants with hydrocephalus: a diffusion tensor imaging study. AJNR Am J Neuroradiol 30:1792-1798

52. Yuan W, Air E, Altaye M, Holland S, Jones B, Bierbrauer K, Mangano F (2009) Abnormal fractional anisotropy in hydrocephalic children: a DTI study. Cerebrospinal Fluid Res 6:S14

53. Kriebel RM, Shah AB, McAllister JP II (1993) The microstructure of cortical neuropil before and after decompression in experimental infantile hydrocephalus. Exp Neurol 119:89-98

54. Eskandari R, McAllister JP 2nd, Miller JM, Ding Y, Ham SD, Shearer DM, Way JS (2004) Effects of hydrocephalus and ventriculoperitoneal shunt therapy on afferent and efferent connections in the feline sensorimotor cortex. J Neurosurg 101:196-210

55. Lovely TJ, Miller DW, McAllister JP 2nd (1989) A technique for placing ventriculoperitoneal shunts in a neonatal model of hydrocephalus. J Neurosci Methods 29:201-206

56. Wright LC, McAllister JP 2nd, Katz SD, Miller DW, Lovely TJ, Salotto AG, Wolfson BJ (1990) Cytological and cytoarchitectural changes in the feline cerebral cortex during experimental infantile hydrocephalus. Pediatr Neurosurg 16:139-155

57. Hochwald GM, Sahar A, Sadik AR, Ransohoff J (1969) Cerebrospinal fluid production and histological observations in animals with experimental obstructive hydrocephalus. Exp Neurol 25:190-199

58. Sahar A, Hochwald GM, Sadik AR, Ransohoff J (1969) Cerebrospinal fluid absorption in animals with experimental obstructive hydrocephalus. Arch Neurol 21:638-644

59. Chumas PD, Drake JM, Del Bigio MR, da Silva MC, Tuor UI (1994) Anaerobic glycolysis preceding white-matter destruction in experimental neonatal hydrocephalus. J Neurosurg 80:491-501
60. Heemskerk AM, Leemans A, Plaisier A, Pieterman K, Lequin MH, Dudink J (2013) Acquisition guidelines and quality assessment tools for analyzing neonatal diffusion tensor MRI data. AJNR Am J Neuroradiol 34:1496-1505

61. Le Bihan D, Mangin JF, Poupon C, Clark CA, Pappata S, Molko N, Chabriat H (2001) Diffusion tensor imaging-concepts and applications. J Magn Res Imag 13:534-546

62. Ciumas C, Saignavongs M, Ilski F, Herbillon V, Laurent A, Lothe A, Heckemann RA, de Bellescize J, Panagiotakaki E, Hannoun S, Marinier DS, Montavont A, Ostrowsky-Coste K, Bedoin N, Ryvlin P (2014) White matter development in children with benign childhood epilepsy with centro-temporal spikes. 137(Pt 4):1095-1106

63. Teipel SJ, Walter M, Likitjaroen Y, Schonknecht P, Gruber O (2014) Diffusion tensor imaging in Alzheimer's disease and affective disorders. Eur Arch Psychiatry Clin Neurosci (in press)

64. Amlien IK, Fjell AM (2014) Diffusion tensor imaging of white matter degeneration in Alzheimer's disease and mild cognitive impairment. Neuroscience. doi:10.1016/j.neuroscience.2014.02.017

65. Langevin LM, Macmaster FP, Crawford S, Lebel C, Dewey D (2014) Common white matter microstructure alterations in pediatric motor and attention disorders. J Pediatr 164(5):1157-1164

66. Mahoney CJ, Ridgway GR, Malone IB, Downey LE, Beck J, Kinnunen KM, Schmitz N, Golden HL, Rohrer JD, Schott JM, Rossor MN, Ourselin S, Mead S, Fox NC, Warren JD (2014) Profiles of white matter tract pathology in frontotemporal dementia. Hum Brain Mapp. doi:10.1002/hbm.22468

67. Kaur S, Powell S, He L, Pierson CR, Parikh NA (2014) Reliability and repeatability of quantitative tractography methods for mapping structural white matter connectivity in preterm and term infants at term-equivalent age. PLoS One 9:e85807

68. Song YJ, Korgaonkar MS, Armstrong LV, Eagles S, Williams LM, Grieve SM (2014) Tractography of the brainstem in major depressive disorder using diffusion tensor imaging. PLoS One 9:e84825

69. Zhang X, Li B, Shan B (2014) Age-related white matter degradation rule of normal human brain: the evidence from diffusion tensor magnetic resonance imaging. Chin Med J 127:532-537

70. George E, Heier L, Kovanlikaya I, Greenfield J (2014) Diffusion tensor imaging of pyramidal tract reorganization after pediatric stroke. Childs Nerv Syst 30(6):1135-1139

71. Calabrese E, Du F, Garman RH, Johnson GA, Riccio C, Tong LC, Long JB (2014) Diffusion tensor imaging reveals white matter injury in a rat model of repetitive blast-induced traumatic brain injury. $\mathrm{J}$ Neurotrauma 31(10):938-950

72. Sun SW, Liang HF, Mei J, Xu D, Shi WX (2014) In vivo diffusion tensor imaging of amyloid-beta-induced white matter damage in mice. J Alzheimers Dis 38:93-101

73. Teipel SJ, Grothe M, Lista S, Toschi N, Garaci FG, Hampel H (2013) Relevance of magnetic resonance imaging for early detection and diagnosis of Alzheimer disease. Med Clin North Am 97:399 424

74. Jurcoane A, Keil F, Szelenyi A, Pfeilschifter W, Singer OC, Hattingen E (2014) Directional diffusion of corticospinal tract supports therapy decisions in idiopathic normal-pressure hydrocephalus. Neuroradiology 56:5-13

75. Ivkovic M, Liu B, Ahmed F, Moore D, Huang C, Raj A, Kovanlikaya I, Heier L, Relkin N (2013) Differential diagnosis of normal pressure hydrocephalus by MRI mean diffusivity histogram analysis. AJNR Am J Neuroradiol 34:1168-1174

76. Koyama T, Marumoto K, Domen K, Miyake H (2013) White matter characteristics of idiopathic normal pressure hydrocephalus: a diffusion tensor tract-based spatial statistic study. Neurol Med Chir (Tokyo) 53:601-608

77. Marumoto K, Koyama T, Hosomi M, Kodama N, Miyake H, Domen K (2012) Diffusion tensor imaging in elderly patients with idiopathic normal pressure hydrocephalus or Parkinson's disease: diagnosis of gait abnormalities. Fluids Barriers CNS 9:20 
78. Kanno S, Abe N, Saito M, Takagi M, Nishio Y, Hayashi A, Uchiyama M, Hanaki R, Kikuchi H, Hiraoka K, Yamasaki H, Iizuka O, Takeda A, Itoyama Y, Takahashi S, Mori E (2011) White matter involvement in idiopathic normal pressure hydrocephalus: a voxel-based diffusion tensor imaging study. J Neurol 258(11):19491957

79. Kim MJ, Seo SW, Lee KM, Kim ST, Lee JI, Nam DH, Na DL (2011) Differential diagnosis of idiopathic normal pressure hydrocephalus from other dementias using diffusion tensor imaging. AJNR AmJ Neuroradiol 32:1496-1503

80. Hattori T, Yuasa T, Aoki S, Sato R, Sawaura H, Mori T, Mizusawa H (2011) Altered microstructure in corticospinal tract in idiopathic normal pressure hydrocephalus: comparison with Alzheimer disease and Parkinson disease with dementia. AJNR Am J Neuroradiol 32: $1681-1687$

81. Hattingen E, Jurcoane A, Melber J, Blasel S, Zanella FE, NeumannHaefelin T, Singer OC (2010) Diffusion tensor imaging in patients with adult chronic idiopathic hydrocephalus. Neurosurgery 66:917924

82. Osuka S, Matsushita A, Yamamoto T, Saotome K, Isobe $\mathrm{T}$, Nagatomo Y, Masumoto T, Komatsu Y, Ishikawa E, Matsumura A (2010) Evaluation of ventriculomegaly using diffusion tensor imaging: correlations with chronic hydrocephalus and atrophy. J Neurosurg 112:832-839

83. Keong NC, DeVito E, Harding S, Gillard JH, Pickard JD (2008) Modelling normal pressure hydrocephalus using diffusion tensor imaging. Clin Neurol Neurosurg 110:S4

84. Castillo EM, Fletcher JM, Li Z, Hoskison MM, Hasan KM, Passaro A, Papanicolaou AC (2009) Transcallosal connectivity and cortical rhythms: findings in children with spina bifida. NeuroReport 20: 1188-1192

85. Hasan KM, Sankar A, Halphen C, Kramer LA, Ewing-Cobbs L, Dennis M, Fletcher JM (2008) Quantitative diffusion tensor imaging and intellectual outcomes in spina bifida: laboratory investigation. J Neurosurg Pediatr 2:75-82

86. Yuan W, Deren KE, McAllister JP 2nd, Holland SK, Lindquist DM, Cancelliere A, Mason M, Shereen A, Hertzler DA, Altaye M, Mangano FT (2010) Diffusion tensor imaging correlates with cytopathology in a rat model of neonatal hydrocephalus. Cerebrospinal Fluid Res 7:19

87. Griffith JL, Shimony JS, Cousins SA, Rees SE, McCurnin DC, Inder TE, Neil JJ (2012) MR imaging correlates of white-matter pathology in a preterm baboon model. Pediatr Res 71:185-191

88. Budde MD, Janes L, Gold E, Turtzo LC, Frank JA (2011) The contribution of gliosis to diffusion tensor anisotropy and tractography following traumatic brain injury: validation in the rat using Fourier analysis of stained tissue sections. Brain 134:2248-2260

89. Xie M, Tobin JE, Budde MD, Chen CI, Trinkaus K, Cross AH, McDaniel DP, Song SK, Armstrong RC (2010) Rostrocaudal analysis of corpus callosum demyelination and axon damage across disease stages refines diffusion tensor imaging correlations with pathological features. J Neuropathol ExpNeurol 69:704-716

90. Klawiter EC, Schmidt RE, Trinkaus K, Liang HF, Budde MD, Naismith RT, Song SK, Cross AH, Benzinger TL (2011) Radial diffusivity predicts demyelination in ex vivo multiple sclerosis spinal cords. Neuroimage 55:1454-1460

91. Budde MD, Frank JA (2010) Neurite beading is sufficient to decrease the apparent diffusion coefficient after ischemic stroke. ProcNatlAcadSci USA 107:14472-14477 